on the 4 th, and this is the highest ever observed in the month of October; on the $51 \mathrm{~h}, 76^{\circ}$ was registered, which corresponds with the temperature observed on October 4, 1859. The return of the Meteorological Office show that $80^{\circ}$ was observed on the $4^{\text {th }}$ in London and at Cambridge, whilst $77^{\circ}$ was registered at several stations in the east of England and in the Midland Counties.

It is difficult to make any satisfactory comparison with previous records, cxcept at one or two places, but these tend to show that so high a temperature at this season does not occur more than about twice in a century. Chas. HAR DING

\section{VOLCANOES OF JAPAN}

THE last number (vol. ix. part 2) of the Transactions of the Seismological Society of Japan is wholly occupied by a paper of Prof. Milne's, on Japanese volcanoes, which is the longest contribution that has yet appeared in the Society's Transactions. The paper is partly historical and partly scientific, and contains, so far as the writer has been able to collect, references to everything that is known on the subject. Very much comes from his own observations, for he has travelled over the greater part of Japan, and has ascended many of the volcanoes. The paper also contains an epitome of some thirty or forty works in Japanese. On the whole, it is a systematic account of material which has been accumulating for the last eleven years.

The following are the more important conclusions which Prof, Milne has formulated in the paper :-

I. Number of Volcanoes.-As Japan has not yet been completely explored, and, moreover, as there is considerable difficulty in defining the kind of mountain to be regarded as a volcano, it is impossible to give an absolute statement as to the number of volcanoes in the country. If under the term volcano be included all mountains which have been in a state of eruption within the hist rital period, those which have a true volcanic form, together with those which still exhibit on their flanks matter ejected from a crater, we may conclude that there are at least rco such mountains in the Japanese Empire. If to this list be added the ruins and basalt wrecks of volcanic cones, the number would be considerably increased. These mountains are distributed as follows:-

\begin{tabular}{|c|c|}
\hline Northern Region.. & $\{$ Kuriles...$\ldots \ldots \ldots \ldots \ldots \ldots \ldots \ldots \ldots$ \\
\hline 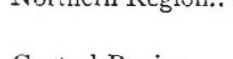 & $\left(\begin{array}{l}\text { Yezo } \\
\text { Northern main island }\end{array}\right.$ \\
\hline Central Region & $\left\{\begin{array}{ll}\text { Central } & , \\
\text { Oshima group } & \ldots . . . . . .\end{array}\right\}$ \\
\hline Southern Region.. & $\left\{\begin{array}{l}\text { Southern main island } \ldots \\
\text { Kitshiu............. } \\
\text { Southern islands }\end{array}\right\}$ \\
\hline
\end{tabular}

Of this number about 48 are still active, or have been so during the historical period. These active volcanoes are distributed as follows :-

$$
\begin{aligned}
& \text { Northern Region.. }\left\{\begin{array}{l}
\text { Kuriles ....... I6 } \\
\text { Yezo ......... I I }
\end{array}\right\} \ldots \ldots \ldots \ldots .27 \\
& \text { Central Region................................. I2 } \\
& \text { Southern Region ............................... } 9 \\
& \text { Total ................ } \overline{48}
\end{aligned}
$$

From this it will be seen that volcanic activity in Japan decreases from the north towards the south.

2. Number of Eruptions. - Altogether about 232 eruptions have been recorded, and of these the greater number took place in the southern districts. This may perhaps be accounted for by the fact that Japanese civilisation advanced from the south. In consequence of this, records were made of various phenomena in the south when the northern districts were still unknown and unexplored regions. The greater number of eruptions took place in February and April. Comparing the frequency of eruptions in the different seasons, the volcanoes of Japan appear to have followed the same law as the earthquakes, a greater number having taken place during the cold months. This winter frequency of volcanic eruptions may possibly be accounted for in the same manner that Dr. Knott accounted for the winter frequency of earthquakes. During the winter months the average barometric gradient across Japan is steeper than in summer. This, coupled with the piling up of snow in the northern regions, gives rise to long-continued stresses, in consequence of which certain portions of the earth's crust are more prepared to give way during the winter months than they are in summer.

3. Position and Relative Age of 7 apanese Volianoes. - The youngest of the Japanese volcanoes appear to be those which exist as, or on, small islands. On the islands in the Kuriles, in the Oshima group, and in the Satsuma sea, many of the volcanoes are yet young and vigorous. Moreover, many of these islands have been formed during the historical period. The island-forming period in the Satsuma sea, for example, was about the year 1780 .

The volcanoes of Japan form a long chain running from N.E. towards S.W.; but a closer examination of the distribution of the volcanic vents shows that there are probably four lines :-

(a) The N.E.-S.W. line running from Kamchatka through the Kuriles and Northern Yezo.

(b) The curved line following the backbone of the main island, and terminating on the western side of the Yezo anticlinal.

(c) The N.N.W.-S.S.E. line of the Oshima group. This line, coming from the Ladrones, passes through Oshima and Fujisan parallel to and near to the line of a supposed fault. Here it intersects the main line running through the main island. Volcanic vents are here very numerous. As the main island line is intersected, while the Oshima line is the intersector, it may be argued that the Oshima-Fujisan line of volcanoes are younger than many of those on the main island line.

(d) The Satsuma line, coming from the Philippines through Sakurajima and culminating in the famous Mount Aso, which is the nucleus of Kiushiu.

4. Lithological and Chemical Character of Lavas.-Although Prof. Milne has made an extensive collection of the volcanic rocks of Japan, the opportunity for examining them has not yet presented itself, and therefore he can only speak of them in general terms. They are at present being carefully studied by the officers of the Geological Survey. The rocks in his possession are chiefly andesites. Those containing augite, like the rocks of Fujisan, closely approximate to basalts. True basalt is, however, rare. Another common rock is hornblende andesite, some of which contains free quartz. Quartz trechytes occur in the north of Japan. The following table shows the percentages of silica, and ferrous and ferric oxide, contained in the rocks of ten volcanoes :-

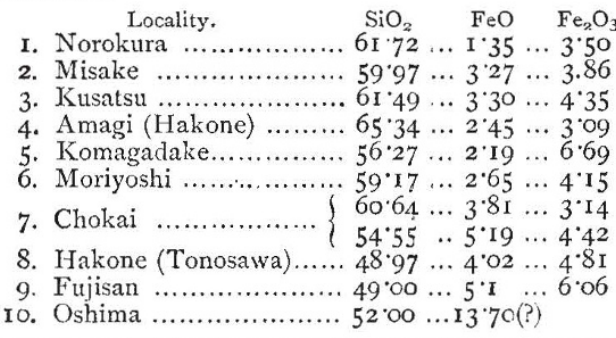

One feature exhibited by the table is that the rocks of Oshima, Fujisan, and Tonosawa are basic, while those like Chokaisan and Moriyoshiyama belonging to the line of volcanoes of the main island, are relatively acidic. More extended observations of this description may show that different lines of volcanoes have thrown out different lavas, or that the lavas of different constitution are of different ages.

5. Magnetic Character of Rocks. - In a study of the soils in the neighbourhood of Tokio, Mr. E. Kinch refers specially to the magnetite they contain. A great portion of this comes from the disintegration of volcanic rocks. Many of the Japanese lavas have a distinct effect upon a compass needle, and many of the black lavas from the crater of Fujisan wiil easily turn the needle of an ordinary compass through $360^{\circ}$. Many of the pieces of lava are not only magnetic but polar. Dr. Naumann found a block of augite trachyte on the top of Moriyoshiyama which would deflect the needle of a compass through $155^{\circ}$. The most curious observation made by this investigator was that the magnetic declination near Gaujusan has during the last eighty years (when it was about $14^{\circ} 30^{\prime} \mathrm{E}$.) decreased $19^{\circ}$, being now about $5^{\circ} \mathrm{W}$. As we recede from this mountain the amount of 
change is less. Assuming this result to be correct, it would seem justifiable to look to Gaujusan as connected with these local changes. Some of the volcanoes in the Kuriles are said to exert a marked influence upon the compasses of ships. When a vessel is lying near certain mountains, as, for instance, in Bear Bay at the north end of Iturup, a distant mountain will have a very different bearing to that which is indicated by the same compass when the vessel is a short distance outside Bear Bay. In both cases the ship may be lying in the same direction, and the direction of observation is practically along the same line. This leads Prof. Milne to urge, as he has already done, that a magnetic observatory should be placed on or near one of the nine active volcanoes of Japan. Changes in volcanic activity are probably accompanied by local changes in the magnetic effects produced by subterranean volcanic magmas. These changes may be due to alterations in position, alterations in chemical constitution, and changes due to the acquisition or loss of heat. If such is the case, he argues, the records of a magnetic observatory would lead up to a knowledge of the changes taking place beneath the ground. When it is remembered that volcanoes like Oshima (Vries Island), where it seems probable that there may be local and rapid changes in magnetic variation taking place, lie in the track of so many vessels, the proposed investigation has a practical as well as a scientific aspect. An investigation of earth-currents at and near volcanoes might be added to the magnetic investigations.

6. Intensity of Eruptions. - It appears from the accounts of eruptions which are given in the paper that the intensity of volcanic action in Japan has been as great as in any other part of the world. One period of unusual activity was between the years $I 780$ and 1800 , a time when there was great activity elsewhere in the globe. It was during this period that part of Mount Unsen was blown up, and from 27,000 to 53,000 persons (according to different accounts) perished, that many islands were formed in the Satsuma sea, that Sakurajima threw out so much pumice material that it was possible to walk a distance of 23 miles upon the floating debris in the sea, and that Asama ejected so many blocks of stone-one of which is said to have been 42 feet in diameter-and a lava-stream 68 kilometres in length.

7. The Form of Volcanoes. - The regular so-called conical form is very noticeable in many of the Japanese mountains, especially perhans in those of recent origin. Outlines of these volcanoes, as exhibited either by sketches or photographs, show curvatures which are similar to each other. From a collection of photographs Prof. Milne traced the profiles of a number of important mountains in Japan. These are reproduced in the paper (see Fig. I). From an examination of these figures he found that the

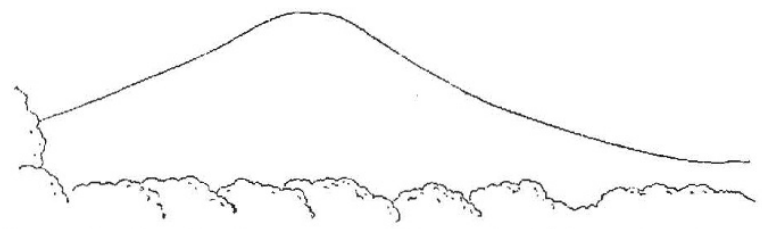

FiG. r.-Outline of Fujiyama, from a photugraph. This may be taken as typical of many Japanese volcanoes.

curvature of a typical volcano was logarithmic, or, in other words, the form of such a mountain was such as might be produced by the revolution of a Jogarithmic curve round its asymptote. In his original paper on the subject he said that the form agreed with that which would be produced by the piling up of loose material. He ought to have said it was the form assumed by a self-supporting mass of coherent material. Mr. George $\mathrm{F}$. Becker (American Fournal of Science, October I 885) continues these observations by an analytical investigation of the conditions of such equilibrium. If the height of a column is $a$, its radius $y$, the distance of any horizontal plane from the base $x$, the specific gravity of the material $\rho$, and the co-efficient of resistance to crushing at the elastic limit $k$, then the equation of the curve, which by its revolution about the $x$ axis will generate the finite unloaded column of the "least variable resistance" is -

$$
\frac{y}{c}=\frac{e^{-\frac{x}{c}}-e^{\frac{x}{c}}}{2},
$$

where

$$
c=\frac{2 k}{\rho}
$$

This latter quantity is of course different for different materials. It can be expressed in terms of $x$ and $y-$

$$
\frac{2 k}{\rho}=\frac{y}{\left(\tan ^{2} d-\mathrm{I}\right)^{-\frac{2}{2}}},
$$

$d$ being the angle which the tangent at any point makes with the $x$ axis. The value of $c$ can be obtained from photographs or drawings of a mountain, while $\rho$ may be obtained from pendulum experiments or from specimens of volcanic material. With these data we can determine the modulus of resistance at the elastic limit of the materials which compose a mountain on a large scale for many constituents of the earth's crust. Mr. Becker concludes his observations by remarking that a study of the form and dimensions of lunar volcanoes would lead to values of $\frac{k}{\rho}$, from whence we might approximately determine whether the lunar lava is similar to that of terrestrial origin. In the table which follows, Prof. Milne has followed out Mr. Becker's suggestion, and calculated the modulus of resistance to crushing at the elastic limit in pounds per square foot for a number of Japanese mountains. The different values for $\frac{2 k}{\rho}$ for the same mountain is in great measure due to the absence of an accurate scale for the various photographs which had to be investigated. Another difficulty was obtaining a value for $r$, or the density of the mountain. Prof. Mendenhall, who made a number of experiments with pendulums on the summit of Fujisan, says the rocks of that mountain have a density of $1 \cdot 75$. This is when they have air in their pores. As powder the density becomes 2.5 . Wada gives the specific gravity of the rock on Fujisan as $2 \cdot 6$.

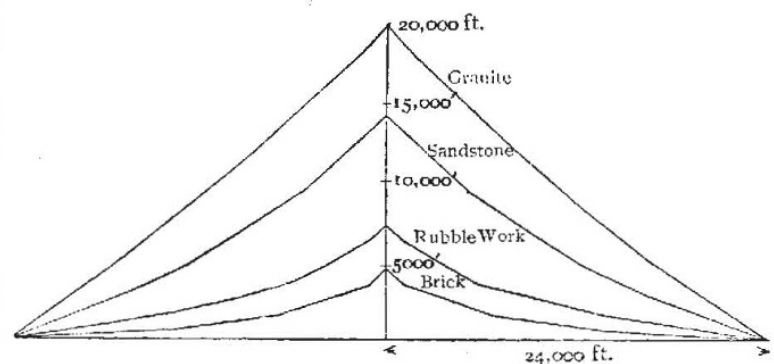

FIG. 2.-Theoretical Mountains.

Assuming the density of the earth at 5.67 , then the density of Fujisan, as determined by Prof. Mendenhall's experiments, is 2 *8. In the following table the density of the materials of all the mountains mentioned is taken at 2.5 .

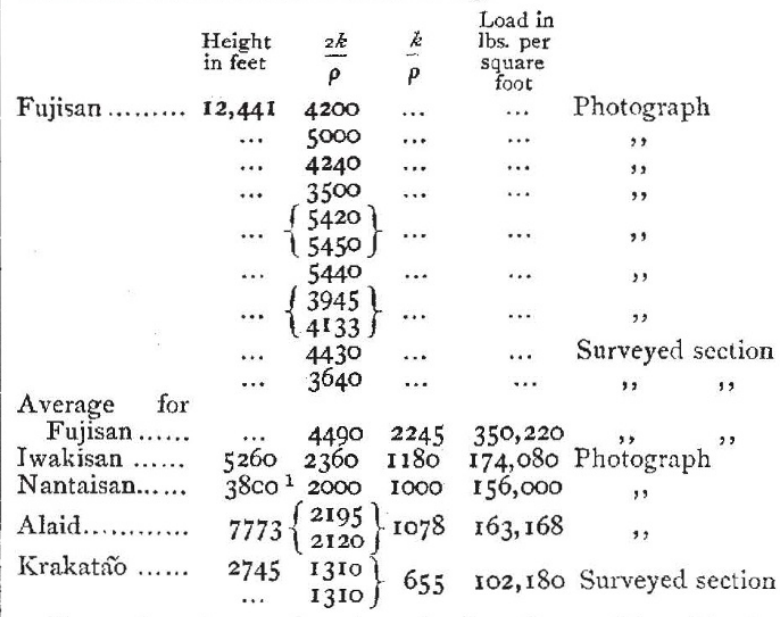

Comparing the results given in the above table with the numbers given in the next section, which are based on experiI This is the height above Lake Chuzenji. 
ments referred to in Rankine's "Civil Engineering," it may be said that the average strength of Fujisan lies between that of rubble work and sandstone; Iwakisan, Nantaisan, and Alaid are like good rubble masonry, while the strength of the ill-fated Krakatao is not much above that of ordinary brickwork.

8. Theoretical Mountains. - As it might be interesting to compare actual mountains with theoretical mountains constructed from the equation-

$$
y=\frac{c}{2}\left(e^{\frac{n}{c}}-e^{-\frac{n}{c}}\right)
$$

such mountains have been drawn, and are shown in Fig. 2. The values of $c$ are given in the following table.

In drawing up the table the instantaneous breaking strength of granite and its crumbling strength, which is the largest possible value for $k$, are taken as being equal. For sandstone the crumbling strength is assumed to be three-fourths of the break ing strength, while for rubble work and brickwork it has been taken as one-half.

\begin{tabular}{|c|c|c|c|c|}
\hline Material & $\begin{array}{l}\text { Instantaneous } \\
\text { breaking strength } \\
\text { in lbs. square feet }\end{array}$ & $\begin{array}{l}\text { Crumbling } \\
\text { strength or } \\
k \text { in lbs. }\end{array}$ & $\begin{array}{l}\text { Weight } \\
\text { cubic } \\
\text { foot lbs. }\end{array}$ & $c=\frac{2 k}{\rho}$ \\
\hline Gran & .. $\quad 1,584, \infty$ & $1,580,000$ & 170 & \\
\hline$\ldots$ & .. $\quad 790,000$ & 590,000 & 144 & \\
\hline Rubble masonry & 316,000 & 150,000 & 120 & \\
\hline Brickwork & 144,000 & 72,000 & II2 & \\
\hline
\end{tabular}

The diameter of the base of each of these mountains is 48,000 feet, and the height to which mountains of the following different materials could be built upon such a base without crushing would approximately be :-

Brickwork ........ 4,600 feet | Sandstone...... 14,500 feet

Rubble masonry .. 7,300 ,, $\quad$ Granite ......... 20,000 ",

9. Causes Modifying Volcanic Forms. - Causes modifying the natural curvature of a mountain are :-

(I) The tendency during the building up of the mountain of the larger particles to roll farther down the mountain than the smaller particles.

(2) The effects of atmospheric denudation, which carries materials from the top of the mountain down towards the base.

(3) The position of the crater, and the direction in which the materials are ejected.

(4) The existence of parasitic craters on the flanks of a mountain.

(5) The direction of the wind during an eruption.

(6) The sinking of a mountain in consequence of evisceration beneath its base.

(7) The expansions and contractions at the base of a mountain due to the acquisition or loss of heat before and after eruptions.

Io. Effect of Volcanic Eruptions on the People.-The eruptions in Japan from time to time have exerted a very marked influence upon the minds of the Japanese people. Divine interference has been sought to prevent eruptions, priests have been ordered to pray, taxes have been repealed, charities have been instituted, special prayers against volcanic disturbances have been formulated, and have remained in use for the period of 100 years, while special days for the annual offering up of these prayers have been appointed. At the present day a form of worship to mountain deities is not uncommon.

\section{SOLUTION 1}

\section{Opening of the Discussion by Prof. Tilden}

FOR want of time, the consideration of various phenomena connected with the subject was necessarily omitted. Thus no reference could be made to the various formulæ relating to expansion or density of solutions, nor to their optical properties, magnetic rotation, nor to the subject of electrolysis. In what follows, a review is presented of the principal phenomena observed in the act of solution of solids (especially metallic salts and other comparatively simple compounds) in liquids, and the chief properties of the resulting solutions, with the object of arriving (if possible) at some conclusion as to the physical explanation of the facts. The question must at once arise whether these phenomena are to be considered as chemical or mechanical, and all the theories which have been put forward to explain the nature of solution are roughly divisible into two classes, according as, on the one hand, they represent the process as a kind of chemical combination, or, on the other, explain the

${ }^{2}$ Report of a discussion at the Birmingham meeting of the British Asso- phenomena by reference to the mechanical intermixture of molecules, or by the influence of the rival attractions of cohesic $n$ in the solid and liquid, and of adhesion of the solid to the liquid. The former hypothesis seems to have. been universally adopted by the older writers, such as Henry and Turner, and it seems pretty clear that Berthollet also regarded solution as an act of chemical combination. Among modern chemists, Prof. Josiah P. Cooke takes a similar view, but $M$. Berthelot is the most consistent and powerful supporter of the same hypothesis. In his "Mécanique Chimique," tome ii. p. I6o, will be found a very clear and formal statement of the views upon this subject which, it is interesting to know, are retained by $M$. Berthelot without modification in any essential particular.

On the other hand, there are a number of writers who, whilst referring the phenomena of solution to a molecular attraction of some kind, do not attribute solubility to the formation of chemical compounds of definite composition. Graham distinctly ranges himself on this side. Brande also appears to have taken a similar view; Daniell, Miller, Nicol, and Dossios may be more or less ranked with them. A theory differing in some important respects from those of the above writers was briefly enunciated in a paper communicated to the Royal Society by Tilden and Shenstone in 1883 . In discussing the connection between fusibility and solubility of salts, the authors point out that the facts tend to "support a kinetic theory of solution, based on the mechanical theory of heat. The solution of a solid in a liquid would accordingly be analogous to the sublimation of a solid into a gas, and proceeds from the intermixture of molecules detached from the solid with those of the surrounding liquid. Such a process is promoted by rise of temperature, partly because the molecules of the still solid substance make longer excursions from their normal centre when heated, partly because they are subjected to more violent encounter with the moving molecules of liquid." This theory, however, only relates to the initial stage of the process of solution, and does not sufficiently explain saturation nor the influence of dissolved substances upon vapour-pressure, specific heat, specific volume, \&c. How far is it true that evolution of heat indicates chemical combination: does the evolution of heat which often takes place on dissolving a solid in water, or on adding more water to its solution, indicate the formation of hydrates, i.e. compounds of the dissolved body with water in definite proportions? Thomsen answers this question in the negative ("Thermochemische Untersuch.," Band iii. p. 20).

Take the case of sulphuric anhydride $\left(\mathrm{SO}_{3}\right)$. It is evident from the diagram exhibited that more than half the total evolution of heat occurs on addition of the first molecule of water to the solid substance ; yet the succeeding molecules give quite an appreciable thermal change. At what point in such a curve should we be justified in setting up a distinction between the effect due to chemical combination and that due to other causes, such as the change of volume consequent on dilution or the possible loss of energy from the adjustment of the motion of the molecules of the constituents to the conditions requisite for the formation of a homogeneous liquid, or (though not in the present case) the decomposition of the compound by the water? In the act of solution of the solids, and especially of anhydrous salts in water, the volume of the solution is always less than the sum of the volumes of the solid and its solvent, with the exception of somejammonium salts in which expansion occurs. Similarly the addition of water to a solution is followed by contraction. This contraction may be due to mere mechanical fitting of the molecules of the one liquid into the interspaces between the molecules of the other (see Mendelejeff's abstract in Fourn. Chem. Soc., Feb. I885, p. I 14). This would probably not be attended by loss of energy. Or the contraction may arise from $t h$. readjustment of molecular motion already referred to.

If we know the coefficient of expansion of the liquid and its specific heat, we can calculate the amount of heat evolved for a given contraction. If this is done for sulphuric acid, and many other cases, it is found that, after accounting for the thermal change due to alteration of volume alone, there is a surplus of heat evolved which may really indicate some kind or some amount of chemical combination.

Thomsen has found that as a rule the heat of solution and of dilution are both either positive or negative. Of thirty-five salts examined, only four supply well-marked exceptions. However we may ultimately explain the anomaly exhibited by these salts, the fact remains that the heat evolved or absorbed during the admixture of any substance with water is in every case a continuous function of the quantity of water added. Similarly 